\title{
Early Sexual Debut among Ghanaian Women: Correlates and Psychological Effect
}

\author{
Abdul Rauf Alhassan ${ }^{1},{ }^{1}$ Kasim Abdulai, ${ }^{2}$ and Mohammed Awal Alhassan ${ }^{3}$ \\ ${ }^{1}$ Department of Surgery, Tamale Teaching Hospital, P.O. Box TL 16, Tamale, Ghana \\ ${ }^{2}$ Department of Clinical Nutrition and Dietetics, School of Allied Health Sciences, University of Cape Coast, Ghana \\ ${ }^{3}$ Department of Obstetrics and Gynaecology, Tamale Teaching Hospital, P.O. Box TL 16, Tamale, Ghana
}

Correspondence should be addressed to Abdul Rauf Alhassan; alhassana84@yahoo.com

Received 25 May 2021; Accepted 31 August 2021; Published 14 September 2021

Academic Editor: Arundhati Char

Copyright (c) 2021 Abdul Rauf Alhassan et al. This is an open access article distributed under the Creative Commons Attribution License, which permits unrestricted use, distribution, and reproduction in any medium, provided the original work is properly cited.

\begin{abstract}
Early sexual initiation is linked to an increased risk of HIV/AIDS and other STIs among teenagers, as well as having multiple partners, not using contraception, unintended pregnancy, and illegal abortions. Aim. To identify the correlates and psychological effects of early sexual debut among not-in-union women in Ghana. A descriptive cross-sectional survey was used for this study using data from Ghana Multiple Indicator Cluster Survey (MICS) for the year 2017/2018. SPSS software was used for data analysis, bivariate analysis for association was done using chi-square, and the prediction was done using a binary logistic regression model. The national prevalence of nonmarital early sexual initiation this current study recorded was $56.9 \%$. Predictors variables were age, $15-24 / \geq 35$ years $(\mathrm{AOR}=1.51,1.28-1.78)$, ever educated ( $\mathrm{AOR}=0.50,0.43-0.60)$, urban address $(\mathrm{AOR}=0.85,0.74-0.98)$, married/single $(\mathrm{AOR}=1.23,1.07-1.42)$, cohabitation/single $(\mathrm{AOR}=1.43,1.19-1.72)$, Greater Accra Region/Upper West Region ( $\mathrm{AOR}=0.67,0.49-0.92$ ), and health insurance (AOR $=0.89,0.79-0.998$ ). As the wealth indices of the woman decrease from the richest to poorest, the likelihood of early sexual debut inversely increases: fourth/richest $(\mathrm{AOR}=1.23,1.04-1.45)$, middle/richest $(\mathrm{AOR}=1.31,1.09-1.58)$, second/richest $(\mathrm{AOR}=1.38,1.11-1.72)$, and poorest/richest $(\mathrm{AOR}=1.44,1.12-1.86)$; use of the internet $(\mathrm{AOR}=0.58,0.50-068)$; substance use and alcohol ever use $(\mathrm{AOR}=1.32,1.17-$ 1.49); cigarette ever use $(\mathrm{AOR}=2.58,1.44-4.64)$; contraceptive use $(\mathrm{AOR}=1.31,1.16-1.49)$; and ever heard of $\mathrm{HIV}(\mathrm{AOR}=59$, 0.42-0.82). In conclusion, the prevalence of early sexual debut is still high in Ghana, especially among the northern regions. Several factors predicted early sex debut, and low life satisfaction and happiness were related to early sexual debut.
\end{abstract}

\section{Introduction}

Sub-Saharan African youth continue to be a high-risk population for sexually transmitted infections (STIs), such as HIV/AIDS [1-3]. As a result, it is critical to prioritize this population's sexual and reproductive health, as they are the "window of hope" in the battle against the HIV/AIDS epidemic $[2,4]$. This awareness has informed policies aimed at shielding young people from new infections through behavioral improvement initiatives in some nations, such as Ghana [1-3]. Early sexual initiation is also one of those focused behavioral modification areas.

The term "early sexual debut" commonly refers to having first sexual encounter before the age of 14 [5]. However, some works of literature have that early sexual initiation is sexual encounters that begin before the age of eighteen [6, 7]. Early sex initiation is often regarded as a risky sexual practice due to its negative consequences $[6,7]$. In other words, early sexual initiation is linked to an increased risk of HIV/AIDS and other STIs among teenagers, as well as having multiple partners, not using contraception, unintended pregnancy, and illegal abortions [8]. Early sexual practice at a young age is a public health problem that is now widespread around the world, especially in developing countries [9]. Even though the age at sexual debut varies by location and by person, early adolescent sexual activity continues to be a problem with negative psychosocial and health consequences $[10,11]$. 
One of the big predisposing factors that put youth at risk of HIV/AIDS is an early sexual start. Young people's sexual initiation exposes them to a slew of negative sexual and reproductive health consequences [12]. Young people who start having sex at a younger age are more likely than those who do not to have numerous and simultaneous sex partners, transactional sex, unsafe sexual activity, and contract STIs like HIV $[12,13]$. Early sexual activity has also been linked to an increased risk of unintended pregnancies and poor academic performance, especially among school-aged children [14].

Early sexual debut is common in African settings, with rates ranging from $26.8 \%$ in Nigeria to 55 percent in Ghana $[15,16]$. For adolescents to remain sexually abstinent, a dynamic interplay of variables such as sociocultural, faith, parent, and child connectedness plays a major role in the timing of sexual initiation $[17,18]$. In Turi et al.'s study factors such as region, substance use (e.g., ever chewed khat, $\mathrm{AOR}=2.02,95 \%$ CI: 1.47, 2.77; ever drank alcohol, AOR $=1.83,95 \%$ CI: $1.35,2.48)$ and not knowing about family planning ( $\mathrm{AOR}=4.47,95 \% \mathrm{CI}: 2.22,8.99$ ) were found to have statistically important associations with early sexual debut in teenage females, whereas ever educational history decreases the odds of early sex initiation. An increase in wealth index from the poorest was associated with a decreased chance of early sexual initiation [19]. In another study, women's early sexual intercourse seems to be determined by substance use habits such as alcohol consumption, cigarette smoking, and khat chewing [6]. In a recent study community-level factors such as marriage, wealth, media exposure, and use of alcohol were influencers of early sexual debut in Ghana, Malawi, and Uganda [20].

Although various studies evaluating early initiation of sexual intercourse among youth have been conducted in Ghana, the majority of these studies are institution-based and concentrate on adolescents in school and university settings, except few such as that of Asante et al. [15]. Asante et al.'s study relied on data from the 2014 Ghana Demographic and Health Survey for sexually active youth aged 15 to 24, whereas this current study will rely on data from Ghana Multiple Indicator Cluster Surveys (MICS) sexually active women (15-49 years) focusing on nonmarital initial sexual activity. The study's main aim is to identify the correlates and psychological effects of early sexual debut among not-in-union women in Ghana.

\section{Materials and Methods}

A descriptive cross-sectional survey was conducted using data from the Ghana Multiple Indicator Cluster Survey (MICS) 2017/18. From October 2017 to January 2018, the Ghana Statistical Service surveyed with the assistance of partners such as the Ministry of Health; Ministry of Education; Ministry of Sanitation and Water Resources; Ministry of Gender, Children and Social Protection; Ghana Health Service; and Ghana Education Service. The United Nations Children's Fund (UNICEF) provided technical assistance, and the Statistics for Results Facility-Catalytic Fund pro- vided financial support to UNICEF, KOICA, UNDP, USAID, and the World Bank (SRF-CF).

The sampling frame was the 2010 Ghanaian Population and Housing Census (PHC). All women between the ages of 15 and 49 who were either permanent residents or tourists who stayed in selected households the night before the survey (14609) were included.

2.1. Statistical Analysis. The findings were analyzed using SPSS version 20. (IBM Corp., 2011, NY). Tables with frequencies and percentages were used to explain the effects of categorical variables. The relationship between the dependent and independent variables was determined using the chi-square test. The predictor variables of early sexual initiation were identified using a binary logistic regression model. The statistical significance of the analysis was set at a $P$ value of 0.05 . The early sexual debut was done excluding those women who never had sexual intercourse and those with initial sexual activity from union (marriage or cohabitation).

2.2. Ethical Consideration. UNICEF's MICS team accepted the protocol for using the Ghana Multiple Indicator Cluster Survey 2017/18 dataset for this study. There was no need for ethical approval since this analysis required a secondary examination of a dataset without disclosing the participants' and their households' identities.

\section{Results}

3.1. Sociodemographic Characteristics of Study Participants. The majority of the study participants $(40.6 \%)$ were between the ages of 15 and 24, and the majority (51.2\%) were from rural areas. In terms of marriage, less than half of the respondents (43.5\%) were married. More (13.8\%) of the participants came from the Ashanti Region, with the Akan tribe accounting for $38.2 \%$ of the total. Health insurance coverage was only $56.7 \%$ among the study participants. A significant number $(35.1 \%)$ of the women had a history of alcohol intake, about $92.9 \%$ of them ever heard of HIV/AIDS, and the majority $(85.4 \%)$ had never used the internet. (Tables 1 and 2).

3.2. Prevalence of Early Sexual Initiation among Ghanaian Women. The national prevalence of nonmarital early sexual initiation this current study recorded was $56.9 \%$, and in terms of regional prevalence, the highest $(66.6 \%)$ prevalence was recorded in the Northern Region (now Northern, Savanna, and Northeast regions) and the lowest (39.7\%) prevalence was recorded in the Greater Accra Region (Table 3). Chi-square analysis resulted in a significant relationship between early sexual debut and all independent factors included in this study $(P<0.005)$ (Tables 4 and 5$)$.

3.3. Predictors of Early Sexual Debut among Study Participants. At the bivariate level of analysis, all independent variables were significantly associated with the early sexual debut and hence were further modeled using a binary logistic regression model to identify predictors of early sexual debut. Table 6 presents estimates of the effects of selected 
TABLE 1: Socioeconomic factors of the respondents.

\begin{tabular}{|c|c|c|c|}
\hline & & Frequency & Percentage \\
\hline \multirow{3}{*}{ Age group } & $15-24$ years & 5836 & $40.6 \%$ \\
\hline & $25-34$ years & 3837 & $26.7 \%$ \\
\hline & 35 years and above & 4701 & $32.7 \%$ \\
\hline \multirow{2}{*}{ Ever attended school } & Yes & 11283 & $78.5 \%$ \\
\hline & No & 3091 & $21.5 \%$ \\
\hline \multirow{2}{*}{ Area } & Urban & 7134 & $48.8 \%$ \\
\hline & Rural & 7475 & $51.2 \%$ \\
\hline \multirow{3}{*}{ Marital status } & Married & 6246 & $43.5 \%$ \\
\hline & Cohabitation & 1655 & $11.5 \%$ \\
\hline & Single & 6473 & $45.0 \%$ \\
\hline \multirow{10}{*}{ Region } & Western & 1350 & $9.2 \%$ \\
\hline & Central & 1319 & $9.0 \%$ \\
\hline & Greater Accra & 1830 & $12.5 \%$ \\
\hline & Volta & 1303 & $8.9 \%$ \\
\hline & Eastern & 1440 & $9.9 \%$ \\
\hline & Ashanti & 2022 & $13.8 \%$ \\
\hline & Brong Ahafo & 1323 & $9.1 \%$ \\
\hline & Northern & 1499 & $10.3 \%$ \\
\hline & Upper East & 1170 & $8.0 \%$ \\
\hline & Upper West & 1353 & $9.3 \%$ \\
\hline \multirow{9}{*}{ Ethnicity } & Akan & 5577 & $38.2 \%$ \\
\hline & GA/Dangme & 1142 & $7.8 \%$ \\
\hline & Ewe & 1758 & $12.0 \%$ \\
\hline & Guan & 513 & $3.5 \%$ \\
\hline & Gruma & 600 & $4.1 \%$ \\
\hline & Mole Dagbani & 3212 & $22.0 \%$ \\
\hline & Grusi & 598 & $4.1 \%$ \\
\hline & Mande & 73 & $0.5 \%$ \\
\hline & Other & 1131 & $7.7 \%$ \\
\hline \multirow{2}{*}{ Health insurance } & With insurance & 8152 & $56.7 \%$ \\
\hline & Without insurance & 6222 & $43.3 \%$ \\
\hline \multirow{2}{*}{ Functional difficulties (age 18-49 years) } & Has functional difficulty & 1125 & $9.0 \%$ \\
\hline & Has no functional difficulty & 11403 & $91.0 \%$ \\
\hline \multirow{5}{*}{ Wealth index quintile } & Poorest & 3383 & $23.5 \%$ \\
\hline & Second & 2412 & $16.8 \%$ \\
\hline & Middle & 2680 & $18.6 \%$ \\
\hline & Fourth & 2720 & $18.9 \%$ \\
\hline & Richest & 3179 & $22.1 \%$ \\
\hline
\end{tabular}

predictors on the odds $(\operatorname{Exp}[B])$ of reporting early sexual debut among the respondents.

The age of the woman at the time of the interview predicted history of early sex debut. Women of the age group 15-24 years were 1.5 times more likely to have experienced early sexual debut as compared to women of the age group 35 years and above $(\mathrm{AOR}=1.51,95 \%$, C.I. $=1.28-1.78)$.

Women with a history of education (ever attended school) were 0.5 times more likely to have experienced early sexual debut as compared with women with zero histories of education $(\mathrm{AOR}=0.50,95 \%$, C.I. $=0.43-0.60)$. Women with residence in urban areas were $15 \%$ less likely to have engaged in early sexual debut as compared to those from rural areas $(\mathrm{AOR}=0.85,95 \%$, C.I. $=0.74-0.98)$. At the time of the survey, women in union relationships (marriage or cohabitation) predicted a history of early sexual debut. Those married were likely about 1.2 times to have experienced early child debut as compared to those who were single $(\mathrm{AOR}=1.23,95 \%$, C.I. $=1.07-1.42)$. Also, those in cohabitation relationships were likely about 1.4 times to have experienced early sexual debut as compared to those women who were single $(\mathrm{AOR}=1.43,95 \%$, C.I. $=1.19$ 
TABLE 2: Other exposure factors.

\begin{tabular}{|c|c|c|c|}
\hline & & Frequency & Percentage \\
\hline \multirow{4}{*}{ Frequency of watching TV } & Not at all & 4623 & $32.2 \%$ \\
\hline & Less than once a week & 1473 & $10.2 \%$ \\
\hline & At least once a week & 2321 & $16.1 \%$ \\
\hline & Almost every day & 5957 & $41.4 \%$ \\
\hline \multirow{2}{*}{ Ever used internet } & Yes & 2005 & $14.6 \%$ \\
\hline & No & 11713 & $85.4 \%$ \\
\hline \multirow{2}{*}{ Ever taken alcohol } & Yes & 5040 & $35.1 \%$ \\
\hline & No & 9334 & $64.9 \%$ \\
\hline \multirow{2}{*}{ Ever tried cigarette smoking } & Yes & 130 & $0.9 \%$ \\
\hline & No & 14244 & $99.1 \%$ \\
\hline \multirow{2}{*}{ Ever used a contraceptive method to avoid pregnancy } & Yes & 2367 & $20.7 \%$ \\
\hline & No & 9079 & $79.3 \%$ \\
\hline \multirow{2}{*}{ Ever circumcised } & Yes & 672 & $6.4 \%$ \\
\hline & No & 9787 & $93.6 \%$ \\
\hline \multirow{2}{*}{ Ever heard of HIV or AIDS } & Yes & 13353 & $92.9 \%$ \\
\hline & No & 1020 & $7.1 \%$ \\
\hline
\end{tabular}

TAble 3: Prevalence of nonmarital early sexual debut in Ghana among women.

\begin{tabular}{cccccc}
\hline & & \multicolumn{3}{c}{ Early sexual debut } \\
& No & \multicolumn{2}{c}{ Yes } \\
\hline \multirow{6}{*}{ Western } & 457 & $41.4 \%$ & 646 & $58.6 \%$ \\
& Central & 463 & $43.2 \%$ & 608 & $56.8 \%$ \\
\multirow{5}{*}{ Region } & Greater Accra & 866 & $60.3 \%$ & 569 & $39.7 \%$ \\
& Volta & 399 & $35.6 \%$ & 722 & $64.4 \%$ \\
& Eastern & 497 & $41.8 \%$ & 691 & $58.2 \%$ \\
& Ashanti & 790 & $49.7 \%$ & 801 & $50.3 \%$ \\
& Brong Ahafo & 472 & $43.7 \%$ & 607 & $56.3 \%$ \\
Total & Northern & 358 & $33.4 \%$ & 713 & $66.6 \%$ \\
& Upper East & 299 & $36.4 \%$ & 522 & $63.6 \%$ \\
& Upper West & 335 & $34.4 \%$ & 638 & $65.6 \%$ \\
& & 4936 & $43.1 \%$ & 6517 & $56.9 \%$ \\
\hline
\end{tabular}

-1.72). From regional prediction, the early sexual debut was $33 \%$ less likely for women from the Greater Accra Region when compared to women from the Upper West Region $(\mathrm{AOR}=0.67,95 \%$, C.I. $=0.49-0.92)$. In terms of health, women with health insurance were likely about 0.9 times to have experienced early sexual debut $(\mathrm{AOR}=0.89,95 \%$, C.I. $=0.79-0.998)$. The economic status of the woman is implicated in the prediction of early sexual debut. As the wealth indices of the woman decreases from the richest to poorest, the likelihood of early sexual debut inversely increases: fourth/richest $(\mathrm{AOR}=1.23,95 \%$, C.I. $=1.04$ $-1.45)$, middle/richest $(\mathrm{AOR}=1.31,95 \%$, C.I. $=1.09-1.58)$, second/richest $(\mathrm{AOR}=1.38,95 \%$, C.I. $=1.11-1.72)$, and poorest $/$ richest $(\mathrm{AOR}=1.44,95 \%, \mathrm{C} . \mathrm{I} .=1.12-1.86)$. The use of the internet was a protective variable in the study as those with a history of internet use were $42 \%$ less likely to have engaged in early sexual debut $(\mathrm{AOR}=0.58,95 \%$, C.I.
$=0.50-068$ ). History of substance use (alcohol and cigarettes) predicted early sexual debut. Those with alcohol ever use were 1.3 times more likely to have engaged in early sexual debut $(\mathrm{AOR}=1.32,95 \%$, C.I. $=1.17-1.49)$, and those with cigarette ever use were 2.6 times more likely to have engaged in early sexual debut $(\mathrm{AOR}=2.58,95 \%$, C.I. $=$ 1.44-4.64). Those with a history of contraceptive use were 1.3 times more likely to have engaged in early sexual debut $(\mathrm{AOR}=1.31,95 \%$, C.I. $=1.16-1.49)$. Women who ever heard of HIV were $41 \%$ less likely to have engaged in early sexual debut $(\mathrm{AOR}=59,95 \%$, C.I. $=0.42-0.82)$.

3.4. The Psychological Effect of Early Sexual Debut. Participant life satisfaction was done using the score of the life satisfaction ladder step (numbered from 0 to 10), where 0 represented the lowest life satisfaction and 10 the highest level of satisfaction. Different levels of life satisfaction were specified based on recommendations from the HBSC protocol (http://www.hbsc.org), and similar papers: those with a low score of $0-6$, were classified as unsatisfied, and those with an average score of 7-8 and high scores of 9-10 were classified as satisfied. And with the estimation of overall happiness, respondents were asked would you say you are (1) very happy, (2) somewhat happy, (3) neither happy nor unhappy, (4) somewhat unhappy, and (5) very unhappy? Those with responses of very happy and somewhat happy were classified as happy, and those with responses of neither happy nor unhappy, somewhat unhappy, and very unhappy were classified as unhappy.

This study further identified a significant relationship between overall life satisfaction and early sexual debut. Those without a history of the early sexual debut were more likely about $7 \%$ to be satisfied with life as compared to those with early sexual debut history $(\mathrm{OR}=1.07$, 95\% C.I. 1.021.12). And in terms of overall life happiness, those without a history of the early sexual debut were more likely about 
TABLE 4: Chi-square association between socioeconomic factors and early sex debut.

\begin{tabular}{|c|c|c|c|c|c|}
\hline & & \multicolumn{2}{|c|}{ Early sexual debut } & \multirow{2}{*}{$X^{2}$} & \multirow{2}{*}{$P$ value } \\
\hline & & NO & YES & & \\
\hline \multirow{3}{*}{ Age group } & 15- 24 years & 1230 & 2246 & 143.763 & $\leq 0.001$ \\
\hline & $25-34$ years & 1769 & 1813 & & \\
\hline & 35 years and above & 1937 & 2458 & & \\
\hline \multirow{2}{*}{ Ever attended school } & Yes & 4151 & 4606 & 281.032 & $\leq 0.001$ \\
\hline & No & 785 & 1911 & & \\
\hline \multirow{2}{*}{ Area } & Urban & 2888 & 2638 & 365.675 & $\leq 0.001$ \\
\hline & Rural & 2048 & 3879 & & \\
\hline \multirow{3}{*}{ Marital status } & Married & 2483 & 3318 & 30.666 & $\leq 0.001$ \\
\hline & Cohabitation & 613 & 1013 & & \\
\hline & Single & 1840 & 2186 & & \\
\hline \multirow{10}{*}{ Region } & Western & 457 & 646 & 315.567 & $\leq 0.001$ \\
\hline & Central & 463 & 608 & & \\
\hline & Greater Accra & 866 & 569 & & \\
\hline & Volta & 399 & 722 & & \\
\hline & Eastern & 497 & 691 & & \\
\hline & Ashanti & 790 & 801 & & \\
\hline & Brong Ahafo & 472 & 607 & & \\
\hline & Northern & 358 & 713 & & \\
\hline & Upper East & 299 & 522 & & \\
\hline & Upper West & 335 & 638 & & \\
\hline \multirow{9}{*}{ Ethnicity } & Akan & 2115 & 2429 & 112.867 & $\leq 0.001$ \\
\hline & Ga/Dangme & 458 & 475 & & \\
\hline & Ewe & 661 & 799 & & \\
\hline & Guan & 133 & 282 & & \\
\hline & Gruma & 144 & 324 & & \\
\hline & Mole Dagbani & 898 & 1406 & & \\
\hline & Grusi & 154 & 263 & & \\
\hline & Mande & 20 & 34 & & \\
\hline & Other & 351 & 504 & & \\
\hline \multirow{2}{*}{ Health insurance } & Yes & 3016 & 3538 & 53.266 & $\leq 0.001$ \\
\hline & No & 1920 & 2979 & & \\
\hline \multirow{2}{*}{ Functional difficulties (age 18-49 years) } & Yes & 402 & 597 & 9.316 & 0.002 \\
\hline & No & 4534 & 5480 & & \\
\hline \multirow{5}{*}{ Wealth index quintile } & Poorest & 760 & 1819 & 676.189 & $\leq 0.001$ \\
\hline & Second & 688 & 1310 & & \\
\hline & Middle & 874 & 1307 & & \\
\hline & Fourth & 1055 & 1157 & & \\
\hline & Richest & 1559 & 924 & & \\
\hline
\end{tabular}

$4 \%$ to be happy with life as compared to those with early sexual debut history $(\mathrm{OR}=1.04,95 \%$ C.I. 1.01-1.06) (Table 7).

\section{Discussion}

Early sexual debut is common in African settings, with rates ranging from $26.8 \%$ in Nigeria to 55 percent in Ghana [15, 16]. In this current study, the national prevalence of nonmarital early sexual initiation this current study recorded was $56.9 \%$ and in terms of regional prevalence, the highest
(66.6\%) prevalence was recorded in the Northern Region (now Northern, Savanna, and Northeast regions) and the lowest (39.7\%) prevalence was recorded in the Greater Accra Region.

At the bivariate level of analysis, all independent variables were significantly associated with the early sexual debut and hence were further modeled using a binary logistic regression model to identify predictors of early sexual debut. The age of the woman at the time of the interview predicted history of early sex debut. Women of the age 
TABLE 5: Chi-square association between other exposure factors and early sexual debut.

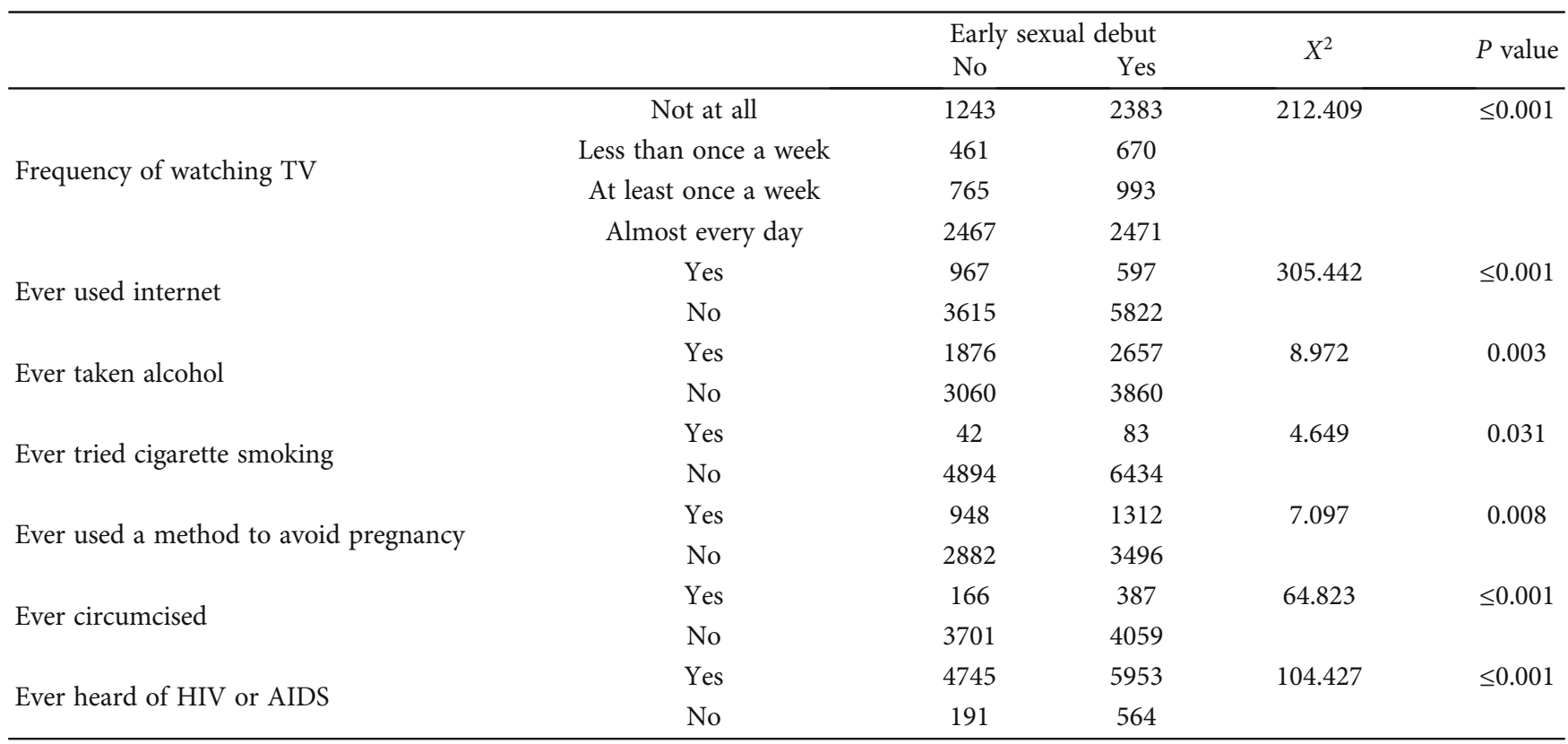

group 15-24 years were likely about 1.5 times to have experienced early sexual debut as compared to women of the age group 35 years and above. Also, in a similar study, the odds of earlier sexual debut history were higher among women of age group 15-19 years as compared to those above 19 years [15].

Also, women with a history of education (ever attended school) were only likely about 0.5 times to present with a history of early sexual debut as compared with women with zero history education. Similar to Asante et al.'s study, females with no formal education and those with only a basic education were more likely to make an early sexual debut [15]. Early sexual activity has also been linked to an increased risk of unintended pregnancies and poor academic performance, especially among school-aged children [14].

From regional prediction, the early sexual debut was $33 \%$ less likely for women from the Greater Accra Region when compared to women from the Upper West Region. Also, similar to Turi et al.'s study, region of the respondents was found to have statistically important associations with an early sexual debut [19]. And women residing in urban areas were $15 \%$ less likely to engage in early sexual debut as compared to those from rural areas, and this was confirmed by Asante et al.'s study that women in rural areas had chances of engaging in early sexual debut as compared to those from rural areas [15]. It has also been suggested that young adults from less-affluent backgrounds believe they have fewer opportunities in life and may lack the educational, job, and leisure motivator compared to those in urban areas $[21,22]$.

It is documented that females with access to modern contraceptives are more likely to engage in sexual activities, which may have affected earlier sexual debut activity. Also, in this present study, those with a history of contraceptive use were likely about 1.3 times to have engaged in early sex- ual debut, and women with health insurance were likely 0.9 times to engage in early sexual debut. Internet access is a source of entertainment and information, and in this study, use of the internet was a protective variable study as those with a history of internet use were $42 \%$ less likely to have engaged in early sexual debut. The risk of an early sexual debut is found to be increased when people had only limited access to the media, and this risk was found to be higher in rural areas [15].

In a recent multicenter study, community-level factors such as marriage were identified as an influencer of early sex debut in Ghana, Malawi, and Uganda [20]. And in this current study, at the time of the survey, women in union relationships (marriage or cohabitation) predicted history of early sexual debut. Those married were about 1.2 times more likely to have experienced early child debut as compared to those who were single. Also, those in cohabitation relationships were likely about 1.4 times to present the history of early sexual debut as compared to those women who were single. However, this study isolated early marriage as a factor of early sex debut.

Individuals who have their first sexual experience at a young age are more likely to participate in risky activities that put them at risk of contracting STIs or HIV. Early sexual debutants are more likely to have a history of STIs and have a higher risk profile, which includes having multiple sex partners, inconsistent condom usage, pay for sex, a history of sexual harassment, and teenage pregnancy [23]. Maybe, this explains the reason why in this present study, women who ever heard of HIV were $41 \%$ less likely to have engaged in early sexual debut.

The economic status of the woman is implicated in the prediction of early sexual debut. As the wealth indices of the woman decrease from the richest to poorest, the likelihood of early sexual debut inversely increases. This is in line 
TABLE 6: Binary logistic regression for predictors of early sexual debut.



with earlier studies which also found household rich wealth status as a protective factor for early sex debut in Ghana $[12,15]$.
History of substance use (alcohol and cigarette) predicted early sexual debut. Those with alcohol ever use were more likely about 1.3 times to engage in early sexual debut, 
TABLE 7: Early nonmarital sexual debut and overall life satisfaction and happiness.

\begin{tabular}{|c|c|c|c|c|c|}
\hline \multirow{6}{*}{ Early sexual debut } & & \multicolumn{2}{|c|}{ Overall life satisfaction } & \multirow{2}{*}{ OR (C.I.) } & \multirow{2}{*}{$P$ value } \\
\hline & & Satisfied & Not satisfied & & \\
\hline & \multirow{2}{*}{ No } & 1899 & 3029 & \multirow{4}{*}{$1.07(1.02-1.12)$} & 0.01 \\
\hline & & $38.5 \%$ & $61.5 \%$ & & \\
\hline & \multirow{4}{*}{ Yes } & 2353 & 4153 & & \\
\hline & & $36.2 \%$ & $63.8 \%$ & & \\
\hline & & \multicolumn{2}{|c|}{ Overall life happiness } & $\Omega D(C \mathrm{D})$ & $D$ whlu \\
\hline & & Happy & Unhappy & UK (C.I.) & $P$ value \\
\hline \multirow{4}{*}{ Early sexual debut } & \multirow{2}{*}{ No } & 3750 & 1186 & \multirow{4}{*}{$1.04(1.01-1.06)$} & 0.01 \\
\hline & & $76.0 \%$ & $24.0 \%$ & & \\
\hline & \multirow{2}{*}{ Yes } & 4778 & 1739 & & \\
\hline & & $73.3 \%$ & $26.7 \%$ & & \\
\hline
\end{tabular}

and those with cigarette ever use were likely about 2.6 times to engage in early sexual debut. In another study, women's early sexual intercourse seems to be determined by substance use habits such as alcohol consumption, cigarette smoking, and khat chewing [6].

Early adolescent sexual activity continues to be a problem with negative psychosocial and health consequences $[10,11]$. The strongest link is discovered in the youngest individuals, with depressed people nearly five times more likely than nondepressed individuals to have had intercourse [24]. And in this present study, in terms of overall life happiness, those without a history of the early sexual debut were more likely about $4 \%$ to be happy with life as compared to those with early sexual debut history. Also, this study further identified a significant relationship between overall life satisfaction and early sexual debut. Those without a history of the early sexual debut were more likely about $7 \%$ to be satisfied with life as compared to those with early sexual debut history. Negative emotional responses to first sexual encounters may also be influenced by psychological factors such as regret or a lack of readiness, which are more common in people who initiate sexual activity early than their on-time initiating peers [25].

Since the research relied on secondary data for interpretation, not all factors related to the subject were examined.

\section{Conclusion}

The prevalence of early sexual debut is still higher in Ghana, especially among the northern regions. Several factors predicted early sex debut, and low life satisfaction and happiness were related to early sexual debut. There is a need for policy enforcement to promote female education and reduce poverty.

\section{Data Availability}

All data related to the findings of this study are available from the Multiple Indicator Cluster Survey (MICS) website upon request.

\section{Conflicts of Interest}

There is no conflict of interest associated with this submission.

\section{Funding}

Funding for this study was accomplished by the authors without any outside funding.

\section{References}

[1] E. Tenkorang and E. Maticka-Tyndale, "Individual- and community-level influences on the timing of sexual debut among youth in Nyanza, Kenya," International Perspectives on Sexual and Reproductive Health, vol. 40, no. 2, pp. 068078, 2014.

[2] UNAIDS, Global AIDS update, Geneva, 2016.

[3] Ghana AIDA commission, "Ghana AIDS country progress report January 2010 to December 2012,” Accra, Ghana, 2013.

[4] J. Kangmennaang, L. Osei, P. Mkandawire, and I. Luginaah, "Circumcision status and time to sexual debut among youth in sub-Saharan Africa: evidence from six demographic and health surveys," AIDS and Behavior, vol. 20, no. 11, pp. 2514-2528, 2016.

[5] L. Richter, M. Mabaso, J. Ramjith, and S. A. Norris, "Early sexual debut: voluntary or coerced? Evidence from longitudinal data in South Africa-the birth to twenty plus study," The South African Medical Journal, vol. 105, no. 4, pp. 304-307, 2015.

[6] F. Mazengia and A. Worku, "Age at sexual initiation and factors associated with it among youths in North East Ethiopia," Ethiopian Journal of Health Development, vol. 23, no. 2, pp. 154-162, 2009.

[7] E. A. Kassahun, A. A. Gelagay, A. A. Muche, A. A. Dessie, and B. A. Kassie, "Factors associated with early sexual initiation among preparatory and high school youths in Woldia town, northeast Ethiopia: a cross-sectional study," BMC Public Health, vol. 19, no. 1, p. 378, 2019.

[8] N. Fetene and W. Mekonnen, "The prevalence of risky sexual behaviors among youth center reproductive health clinics users and non-users in Addis Ababa, Ethiopia: a comparative cross-sectional study," PLoS One, vol. 13, no. 6, article e0198657, 2018. 
[9] D. G. G. Hailu, "Factors early sexual initiation among governmental preparatory school students, Addis Ababa, Ethiopia," Journal of Community Medicine \& Health Education, vol. 5, no. 1, pp. 1-7, 2015.

[10] K. A. Durowade, O. A. Babatunde, L. O. Omokanye et al., "Early sexual debut: prevalence and risk factors among secondary school students in Ido-Ekiti, Ekiti state, South-West Nigeria," African Health Sciences, vol. 17, no. 3, pp. 614-622, 2017.

[11] M. F. Furlanetto, D. M. Ghedin, T. R. Gonçalves, and A. H. Marin, "Individual and contextual factors associated with sexual initiation among adolescents," Psicologia: Reflexão e Crítica, vol. 32, no. 1, p. 25, 2019.

[12] M. Marston, D. Beguy, C. Kabiru, and J. Cleland, "Predictors of sexual debut among young adolescents in Nairobi's informal settlements," International Perspectives on Sexual and Reproductive Health, vol. 39, no. 1, pp. 022-031, 2013.

[13] E. O. Onsomu, J. K. Kimani, B. A. Abuya et al., "Delaying sexual debut as a strategy for reducing HIV epidemic in Kenya," African Journal of Reproductive Health, vol. 17, no. 2, pp. 4657, 2013.

[14] K. Peltzer, "Early sexual debut and associated factors among in-school adolescents in eight African countries," Acta Paediatrica, vol. 99, no. 8, pp. 1242-1247, 2010.

[15] K. O. Asante, E. Nketiah-Amponsah, J. Andoh-Arthur, I. M. Boafo, and S. Ampaw, "Correlates of early sexual debut among sexually active youth in Ghana," International Quarterly of Community Health Education, vol. 39, no. 1, pp. 9-17, 2018.

[16] F. Funmito Omolola, F. Akintunde Olusegun, O. Olumuyiwa A et al., "Prevalence and predictors of early sexual debut among adolescents in Ogbomoso, Nigeria," American Journal of Public Health Research, vol. 6, no. 3, pp. 148-154, 2018.

[17] C. Millera and K. Galbraith, "Family relationships and adolescent pregnancy risk: a research synthesis," Developmental Review, vol. 21, no. 1, pp. 1-38, 2001.

[18] S. Kamal, "Adolescent motherhood in Bangladesh: evidence from 2007 BDHS data," Canadian Studies in Population, vol. 39, no. 1-2, pp. 63-82, 2012.

[19] E. Turi, B. T. Merga, G. Fekadu, and A. A. Abajobir, "Why too soon? Early initiation of sexual intercourse among adolescent females in Ethiopia: evidence from 2016 Ethiopian Demographic and Health Survey," International Journal of Women's Health, vol. 12, pp. 269-275, 2020.

[20] R. Stephenson, C. Simon, and C. Finneran, "Community factors shaping early age at first sex among adolescents in Burkina Faso, Ghana and Uganda," The Journal of Nutrition and Health, vol. 32, no. 2, pp. 161-175, 2014.

[21] S. Babalolaa, B. Kusemijuc, L. Calhoun, M. Corroon, and B. Ajao, "Factors associated with contraceptive ideation among urban men in Nigeria," International Journal of Gynaecology and Obstetrics, vol. 130, pp. 1-14, 2015.

[22] L. Eaton, A. Flisher, and L. Aarø, "Unsafe sexual behaviour in South African youth," Social Science \& Medicine, vol. 56, no. 1, pp. 149-165, 2003.

[23] R. Shrestha, P. Karki, and M. Copenhave, "Early sexual debut: a risk factor for STIs/HIV acquisition among a nationally representative sample of adults in Nepal," Journal of Community Health, vol. 41, no. 1, pp. 70-77, 2016.
[24] D. E. Adimora and A. O. Onwu, "Socio-demographic factors of early sexual debut and depression among adolescents," African Health Sciences., vol. 19, no. 3, pp. 2634-2644, 2019.

[25] R. Wesche, D. A. Kreager, E. S. Lefkowitz, and S. E. Siennick, "Early sexual initiation and mental health: a fleeting association or enduring change?," Journal of Research on Adolescence, vol. 27, no. 3, pp. 611-627, 2017. 